\title{
Spontaneous Self-Distancing and Adaptive Self-Reflection Across Adolescence
}

\author{
Rachel E. White \\ University of Pennsylvania
}

\author{
Ethan Kross \\ University of Michigan
}

\author{
Angela L. Duckworth \\ University of Pennsylvania
}

\begin{abstract}
Experiments performed primarily with adults show that self-distancing facilitates adaptive self-reflection. However, no research has investigated whether adolescents spontaneously engage in this process or whether doing so is linked to adaptive outcomes. In this study, 226 African American adolescents, aged 11-20, reflected on an anger-related interpersonal experience. As expected, spontaneous self-distancing during reflection predicted lower levels of emotional reactivity by leading adolescents to reconstrue (rather than recount) their experience and blame their partner less. Moreover, the inverse relation between self-distancing and emotional reactivity strengthened with age. These findings highlight the role that self-distancing plays in fostering adaptive self-reflection in adolescence, and begin to elucidate the role that development plays in enhancing the benefits of engaging in this process.
\end{abstract}

When children and adults experience strong negative emotions, they often try to make sense of them (e.g., Heider, 1958; Kelly, 1955; Park, 2010). Although this meaning-making process works well at times (e.g., Pennebaker \& Chung, 2007; Wilson \& Gilbert, 2008), it can also break down, leading people to ruminate and feel worse (Nolen-Hoeksema, Wisco, \& Lyubomirsky, 2008), which raises the question: Why do attempts to understand feelings sometimes succeed and other times fail?

According to one line of work performed primarily with adults, the ability to self-distance or "take a step back" when reflecting on emotional experiences plays a critical role in allowing people to work through negative experiences in ways that promote meaning making rather than emotional reactivity (Kross \& Ayduk, 2011). This process could be especially useful in regulating emotions during adolescence, a period characterized by more powerful and frequent negative emotional experiences than any other (Larson, Csikszentmihalyi, \& Graef, 1980; Larson \& Lampman-Petraitis, 1989;

We thank Sarah Patrick, David Meketon, and Benjamin Plummer for assistance with data collection. This research was funded by the John F. Templeton Foundation (21564) to Ethan Kross and Angela L. Duckworth, and Grant K01-AG033182 from the National Institute on Aging to Angela L. Duckworth.

Correspondence concerning this article should be addressed to Rachel E. White, 3701 Market St., Philadelphia, PA 19104. Electronic mail may be sent to rwhi@sas.upenn.edu.
Larson, Moneta, Richards, \& Wilson, 2002). Yet, no research that we are aware of has examined whether the spontaneous activation of self-distancing explains normative differences in adaptive versus maladaptive self-reflection among adolescents.

In the current study, we addressed this question using a developmental framework that allowed us to examine (a) whether spontaneous self-distancing is related to adaptive emotional responses in adolescence and (b) whether the use or efficacy of spontaneous self-distancing strategies varies with age.

\section{Self-Distancing and Emotion Regulation}

Psychological distancing-from the self, the here, the now, or reality-allows us to mentally transcend the immediate, egocentric experience of a situation (Carlson \& Zelazo, 2008; Cocking \& Renninger, 1993; Sigel, 1970; Trope \& Liberman, 2010), a necessary step in exerting conscious control (Carlson \& Zelazo, 2008; Fujita, Trope, Liberman, \& Levin-Sagi, 2006; Liberman \& Trope, 2008; Mischel \& Rodriguez, 1993; Zelazo, 2004). Experiments have demonstrated the benefits of psychological

(C) 2015 The Authors

Child Development (c) 2015 Society for Research in Child Development, Inc. All rights reserved. 0009-3920/2015/8604-0020

DOI: $10.1111 /$ cdev. 12370 
distancing on a variety of self-control tasks in both adults (e.g., Fujita et al., 2006; Kross et al., 2014) and children (e.g., Mischel \& Baker, 1975; Prencipe \& Zelazo, 2005; White \& Carlson, in press). Applied to emotion regulation, psychological distancing attenuates negative emotion by shifting attention away from the concrete details of one's experience, thereby allowing for adaptive self-reflection (Davis, Gross, \& Ochsner, 2011; Gruber, Harvey, \& Johnson, 2009; Katzir \& Eyal, 2013; Kross \& Ayduk, 2011; Ochsner \& Gross, 2008; Wisco \& Nolen-Hoeksema, 2011).

One type of psychological distancing that has proven particularly effective at increasing adaptive self-reflection in experimental contexts is self-distancing, defined as taking an outsider's perspective on the self. For example, in one study, adults were randomly assigned to recall a recent angry experience (Kross, Ayduk, \& Mischel, 2005) through a self-immersed perspective (i.e., through their own eyes) or a self-distanced perspective (i.e., through the eyes of an observer or "fly on the wall"). Analyzing negative experiences from a self-distanced perspective led participants to focus less on recounting the emotional details of the event and more on reconstruing it in ways that promoted insight and closure. In turn, this shift in thought content led to lower levels of emotional reactivity (see also Kross \& Ayduk, 2008, for similar results with sad experiences).

To date, only one experiment has investigated the role that self-distanced reflection plays in allowing children to work through negative past experiences (Kross, Duckworth, Ayduk, Tsukayama, \& Mischel, 2011). Consistent with research on adults, fifth graders who were randomly assigned to reflect on a painful autobiographical experience from a self-distanced perspective, compared to a selfimmersed perspective, were less upset after reflecting on it. This decrease in negative emotion was mediated by a shift in thought content (i.e., more reconstrual and less recounting) as well as a decrease in interpersonal blame. Importantly, despite some research in the clinical domain that equates distancing with emotional detachment (e.g., Foa, Huppert, \& Cahill, 2006; Roecker, Dubow, \& Donaldson, 1996), self-distancing did not lead to avoidance in any of these studies. Rather, it led participants to approach the event with greater objectivity.

But how does self-distancing play out in "real life?" While experiments are instrumental in establishing causality, they cannot illuminate how individuals manage their emotions in vivo. Only recently have researchers begun to address this issue (Ayduk \& Kross, 2010; Grossmann \& Kross, 2010; Verduyn, Van Mechelen, Kross, Chezzi, \& Van Bever, 2012). One recent series of studies (Ayduk \& Kross, 2010) revealed that spontaneous self-distancing, like experimentally manipulated self-distancing, was related to adaptive shifts in the content of adults' thoughts about upsetting situations (i.e., more reconstrual and less recounting) and, in turn, to lower emotional reactivity.

Virtually nothing is known, however, about the development of spontaneous self-distancing. By adulthood, spontaneous self-distancing is an established process (Ayduk \& Kross, 2010; Verduyn et al., 2012), but we do not know when it first makes its way into children's or adolescents' regulatory playbook. If self-distancing follows a similar developmental trajectory to other regulatory strategies, such as distraction or reappraisal, its use should increase from childhood through adolescence (Campos, Frankel, \& Camras, 2004; Garnefski \& Kraaij, 2006; Hodgins \& Lander, 1997; Mischel \& Mischel, 1983; Riediger \& Klipker, 2014; Williams \& McGillicuddy-De Lisi, 1999).

Moreover, we do not know whether the effects of spontaneous self-distancing change with age. Continued maturation of the prefrontal cortex, an area critical to self-regulation (e.g., Casey et al., 2010; Ochsner \& Gross, 2008; Spear, 2000), as well as practice using these strategies (Riediger \& Klipker, 2014) could contribute to increased efficacy of spontaneous self-distancing across adolescence. Consistent with this hypothesis, experiments show that emotion regulation strategies grow in efficacy across adolescence (e.g., McRae et al., 2012). Notably, one recent study showed that increasing perceived spatial distance (a form of psychological distancing) from aversive images attenuated negative affect more in older adolescents than in younger adolescents (Silvers et al., 2012). Together, these data suggest that spontaneous self-distancing could be widely implemented across adolescence, but that its efficacy might increase with age.

\section{The Current Study}

Adolescents were prompted to reflect on a recent anger-inducing experience. They were then asked to indicate the extent to which they spontaneously self-distanced while reflecting on their experience and to report on emotional and interpersonal outcomes related to the experience. We expected greater levels of spontaneous self-distancing during reflection to relate to lower emotional reactivity. 
We further hypothesized that this relation would be mediated by increases in reconstrual (rather than recounting) of the situation and decreases in interpersonal blame, mirroring the mechanisms revealed by previous experimental work (Kross \& Ayduk, 2008; Kross et al., 2005; Kross et al., 2011). Finally, we explored whether the use of self-distancing strategies and their relation to emotional reactivity varied as a function of age across the adolescent period.

\section{Method \\ Participants}

Participants were 236 adolescents from a public middle and high school in Washington, D.C. in the spring of 2013. The sample was entirely African American, reflecting the demographics of the area. Opt-out parental consent and active child assent were obtained for all participants. At the time of testing, $4 \%$ of participants reported that they were unable to recall an anger-inducing event and were therefore excluded from final analyses (final $N=226 ; 56 \%$ female; $M_{\text {age }}=14.43, S D_{\text {age }}=2.06$; range $=11$ to 20 years old).

\section{Procedure and Measures}

Adolescents were tested in a large conference room at their school under the supervision of research staff. Child assent and surveys were administered on laptop computers to groups of approximately 15-20 adolescents using Qualtrics survey software (Qualtrics, Provo, UT).

\section{Memory Prompt}

Following a brief introduction, adolescents were prompted to think of a recent event that made them angry. They received the following series of instructions via audio recording (adapted for adolescents from Kross et al., 2011).

No matter how well two people get along, sometimes there are times when they get very mad at each other, so mad that they feel like they are going to explode. They might get annoyed about something the other person does, get into fights because they are in bad moods, or argue with each other.

Take a few minutes right now to think about a time when you got very mad at someone. Try to remember a specific fight or argument that happened not too long ago and that still makes you upset when you think about it.

Once participants thought of an event that made them angry (recall time: $M=49.50 \mathrm{~s}, S D=15.86$ ), they were cued to close their eyes and recall the experience in their imagination. Finally, when they indicated that they were ready to proceed, they were prompted to reflect on their feelings about the situation for at least $30 \mathrm{~s}$.

Take some time to try to understand the causes and reasons for the thoughts and feelings you experienced. Why did you feel the way you did? What were the causes and reasons for your feelings? Take your time to really understand why you felt the way you did.

\section{Spontaneous Self-Distancing}

Following prior research (Ayduk \& Kross, 2010; Kross et al., 2011), we assessed self-distancing by asking adolescents to rate the following two items immediately after they reflected on their memory: "When you saw the fight again in your imagination a few moments ago, how much did you feel like you were seeing it through your own eyes versus watching the fight happen from a distance (like watching yourself in a movie $)$ ?" $(1=$ completely through my own eyes, 7 = completely from a distance), and "When you saw the fight again in your imagination a few moments ago, how far away from the fight did you feel?" ( 1 = very close, $7=$ very far $)$. (For additional analyses using only these two selfdistancing items, see Appendix S1.)

Given recent research suggesting that various dimensions of distance share the same underlying meaning (Maglio, Trope, \& Liberman, 2013; Trope \& Liberman, 2010), we also collected information on two additional forms of psychological distance in an effort to increase the precision of our measurement. Hypothetical distance was assessed by asking adolescents "When you thought about the fight a few moments ago, how much did it feel real or imagined?" ( $1=$ very real, $7=$ very imagined $)$. Temporal distance was measured by asking, "When you thought about the fight a few moments ago, how long ago did it feel like the fight happened?" ( 1 = right now, $7=$ a long time ago $)$. We averaged ratings on these four questions to compute a spontaneous distancing composite score $(\alpha=.60$, $M=3.58, S D=1.24$. 


\section{Emotional Reactivity}

After the recall exercise, adolescents rated their current emotional state using three items: "Thinking about the event still makes me feel upset (e.g., angry, sad, hurt, rejected)," "When I think about the fight now, my feelings are still pretty strong," and "When I think about the fight now, I feel the same way I did when the fight really happened" ( 1 = completely disagree, $7=$ completely agree). Ratings were averaged to create an emotional reactivity index $(\alpha=.73, \quad M=4.14$, $S D=1.74)$.

\section{Thought Content: Recounting Versus Reconstrual}

Next, adolescents rated the degree to which they recounted (i.e., thought about the specific chain of events that unfolded during their fight) and reconstrued (i.e., realized something that made them think differently or experienced insight regarding the fight) the event. Adolescents rated their agreement $(1=$ completely agree, $7=$ completely disagree $)$ with the statement, "When I thought about this fight, I saw it happening step-by-step, from beginning to end" to operationalize recounting $(M=4.88, \quad S D=1.89)$. Additionally, adolescents rated three reconstrual items: "When I thought about the fight, I realized something that makes me think differently about why I felt the way I did," "When I thought about the fight, I realized something that made the fight bother me less," and "When I thought about the fight, I understood why I reacted the way I did better than when it first happened." Post hoc inspection of adolescents' ratings on the third reconstrual item, regarding understanding, revealed that it was unexpectedly related to greater emotional reactivity $(r=.19, p<.01)$, a pattern opposite to the first two reconstrual items ( $r \mathrm{~s}=-.06$ and -.09 , respectively) as well as previous research (e.g., Ayduk \& Kross, 2010). Therefore, this item was dropped from further analyses (analyses including this item are provided in Appendix S2) and a reconstrual composite was calculated by averaging the two remaining items $(r=.20, p<.01$, $M=4.01, \quad S D=1.55)$. Finally, following prior research (Ayduk \& Kross, 2010; Kross \& Ayduk, 2008; Kross et al., 2005; Kross et al., 2011), we assessed the balance of adaptive versus maladaptive reflection by subtracting reconstrual from recounting such that higher scores reflected the predominance of recounting relative to reconstruing $(M=0.86, S D=2.36)$.

\section{Blame}

Blame was measured through ratings $(1=$ completely disagree, $7=$ completely agree) on the item, "When I thought about this fight, I still blamed the other person" $(M=5.04, S D=2.07)$.

\section{Forgiveness}

Forgiveness was measured through ratings $(1=$ completely disagree, $7=$ completely agree $)$ on the item, "When I thought about this fight, I realized something that makes me forgive the person I fought with" $(M=3.59, S D=2.25)$.

\section{Avoidance}

Avoidance was measured through ratings $(1=$ completely disagree, $7=$ completely agree $)$ on the item, "When I was first asked to remember this fight, I tried not to think about it" $(M=3.55$, $S D=2.29$ ).

\section{Covariates}

Because older memories are inherently more distanced from the here and now than newer memories (Ayduk \& Kross, 2010), we asked adolescents to specify how long ago the incident they described took place (i.e., memory age; $1=a$ few days ago, $2=a$ few weeks ago, $3=a$ month ago, $4=a$ few months ago, $5=a$ year ago or more; $M=3.52$, $S D=1.39, M d n=4)$. Likewise, adolescents were also asked to rate $(1=$ completely disagree, $7=$ completely agree) the accessibility of an angry memory using the item, "It was very hard for me to remember a specific fight when I got very mad at someone" $^{\prime \prime}(M=3.61, S D=2.30)$.

\section{Results \\ Emotional Reactivity}

As predicted, adolescents who engaged in greater levels of spontaneous self-distancing experienced less emotional distress when recalling an anger-inducing experience, $r=-.43, p<.001$. This relation held after controlling for memory age and accessibility, $p r=-.40, p<.001$ (see Table 1).

\section{Thought Content (Recounting-Reconstrual)}

Thought content was negatively related to selfdistancing, $r=-.26, p<.001$, and remained so after 
Table 1

Bivariate and Partial Correlations

\begin{tabular}{|c|c|c|c|c|c|c|c|c|c|}
\hline & Age & Distancing & $\begin{array}{l}\text { Emotional } \\
\text { reactivity }\end{array}$ & Thought content & Blame & Forgive & Avoidance & $\begin{array}{c}\text { Memory } \\
\text { age }\end{array}$ & $\begin{array}{c}\text { Memory } \\
\text { access }\end{array}$ \\
\hline Age & & -.11 & -.02 & -.09 & .09 & .03 & $-.14^{*}$ & -.10 & .01 \\
\hline Distancing & -.10 & & $-.43^{* *}$ & $-.26^{* *}$ & $-.21^{* *}$ & .10 & -.02 & $.17^{*}$ & $.23^{* *}$ \\
\hline Emotional reactivity & -.03 & $-.40^{* *}$ & & $.28^{* *}$ & $.27^{* *}$ & -.11 & $.25^{* *}$ & $-.18^{* *}$ & -.08 \\
\hline Thought content & -.10 & $-.23^{* *}$ & $.27^{* *}$ & & $.15^{*}$ & $-.18^{* *}$ & -.08 & -.09 & $-.13^{\dagger}$ \\
\hline Blame & .07 & $-.19 * *$ & $.25^{* *}$ & $.13^{\dagger}$ & & $-.29 * *$ & -.03 & $-.13^{*}$ & -.07 \\
\hline Forgive & .03 & .06 & -.09 & $-.16^{*}$ & $-.28^{* *}$ & & .08 & .06 & $.19^{* *}$ \\
\hline Avoidance & $-.14^{*}$ & -.04 & $.26^{* *}$ & -.07 & -.02 & .07 & & .01 & .10 \\
\hline Memory age & & & & & & & & & .09 \\
\hline
\end{tabular}

Note. $N=226$. Bivariate correlations are placed above the diagonal. Partial correlations, controlling for memory age and accessibility, are placed below the diagonal.

${ }^{\dagger} p<.10 . * p<.05 . * * p<.01$.

controlling for memory age and accessibility, $p r=-.23, p<.001$, indicating that greater spontaneous self-distancing was associated with decreased predominance of recounting over reconstruing.

\section{Blame and Forgiveness}

Adolescents who distanced themselves more from the experience were less likely to place blame on their partner in the recalled fight, $r=-.21$, $p<.001$. This relation held after controlling for age and accessibility of the memory, $p r=-.19, p<.01$. Self-distancing was not, however, related to forgiving their partner, $r=.10, p=.13$.

\section{Avoidance}

Self-distancing was not related to attempts to avoid thinking about the experience, $r=-.02$, $p=.79$.

\section{Statistical Mediation}

Several previous experiments have established a causal pathway in which thought content (Kross \& Ayduk, 2008; Kross et al., 2005; Kross et al., 2011) and blame (Kross et al., 2005; Kross et al., 2011) mediate the relation between self-distancing and emotional reactivity. In order to determine whether the current data are consistent with this model, we conducted bootstrapping tests (Hayes, 2013) with 10,000 replications (see Figure 1). Indirect effects were significant through thought content (indirect effect $=-0.05$, bootstrapped 95\% CI $[-0.11,-0.01])$ and blame (indirect effect $=-0.05$, bootstrapped $95 \%$ CI $[-0.11,-0.01])$, thus lending support to the possibility that spontaneous self-distancing relates to lower emotional reactivity in adolescents, at least in part, through its relation to the content of one's thoughts about and interpersonal reactions to a negative experience.

\section{Age Effects}

Age was examined as a moderator of the relation between self-distancing and emotional reactivity in a regression model controlling for memory age and accessibility (see Table 2). The strength of the inverse relation between spontaneous self-distancing and emotional reactivity increased significantly across adolescence, $B=-0.14, p<.001$ (see Figure 2). A follow-up Johnson-Neyman analysis (Hayes, 2013; Johnson \& Neyman, 1936) revealed that greater spontaneous self-distancing was significantly related to lower levels of emotional reactivity in all but the youngest participants (> 11.72 years).

\section{Discussion}

This research is the first to demonstrate that adolescents spontaneously self-distance when reflecting on negative memories and that this process is linked to adaptive emotion regulation. In line with previous research with adults (Ayduk \& Kross, 2010), we found that the more adolescents spontaneously self-distanced when reflecting on an angerinducing event, the less they upset they became. Moreover, the way adolescents thought about the event mediated this relation. Specifically, adolescents who self-distanced experienced less emotional reactivity, at least in part, because they blamed others less and focused on reconstruing their fight in meaningful ways (rather than recounting the 


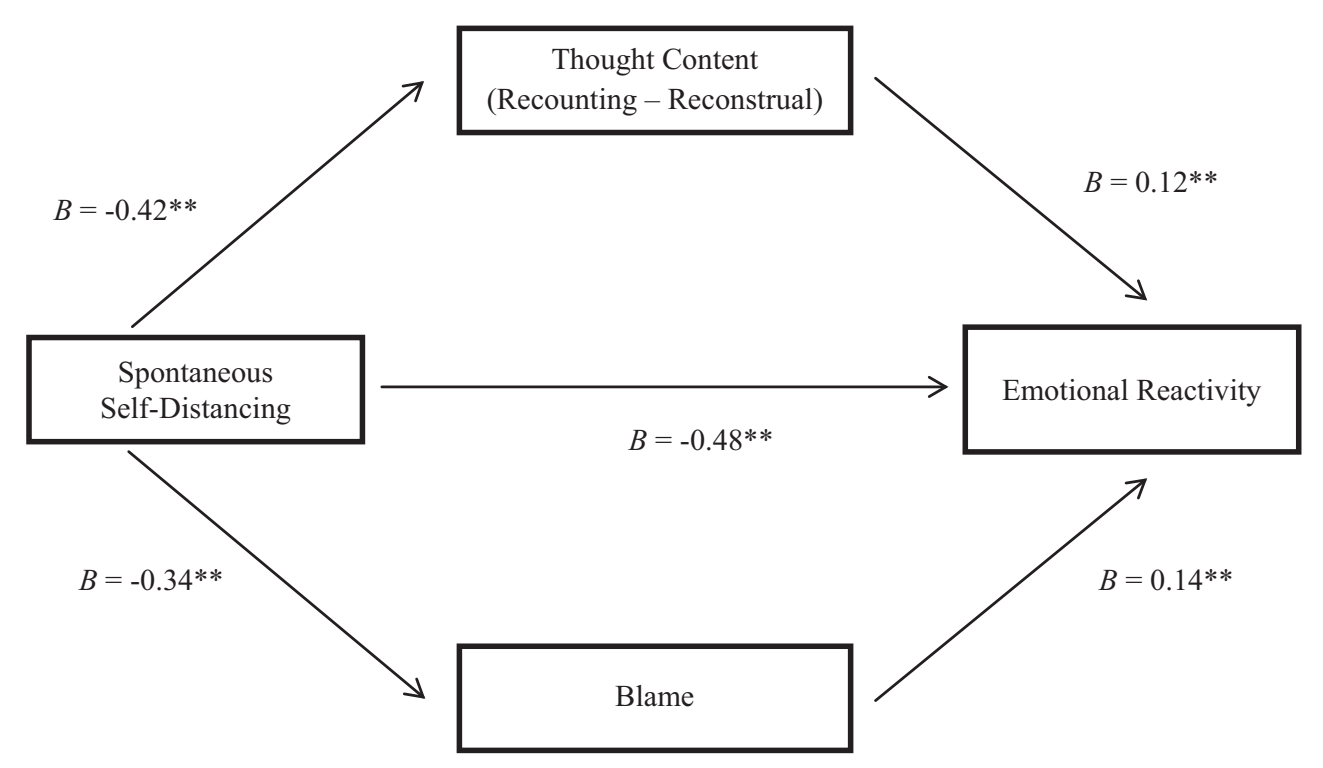

Figure 1. Thought content and blame mediate the relation between spontaneous self-distancing and emotional reactivity $(n=225)$. Analyses controlled for memory age and accessibility. Values represent unstandardized regression coefficients.

$* * p<.01$.

Table 2

Regression Predicting Emotional Reactivity

\begin{tabular}{lrrrc}
\hline & \multicolumn{1}{c}{$B$} & $S E$ & \multicolumn{1}{c}{$t$} & $p$ \\
\hline Constant & 4.42 & 0.33 & 13.35 & $<.001$ \\
Memory age & -0.12 & 0.08 & -1.56 & .12 \\
Memory accessibility & 0.02 & 0.05 & 0.51 & .61 \\
Age & -0.08 & 0.05 & -1.49 & .14 \\
Spontaneous & -0.64 & 0.09 & -7.22 & $<.001$ \\
$\quad$ self-distancing & & & & \\
$\quad$ Spontaneous & -0.14 & 0.04 & -3.40 & $<.001$ \\
$\quad$ Self-Distancing x Age & & & & \\
\hline
\end{tabular}

Note. $N=221 . R=.49, F(5,215)=13.33, p<.001$. Product terms were mean centered prior to analysis.

details). Overall, the current results provide external validity to previous experimental work outlining the causal effects of self-distancing on negative emotion (Kross et al., 2005; Kross et al., 2011) and show that these findings generalize to adolescents and under-studied minority populations. They further suggest that spontaneous self-distancing could play an important role in "real-life" adolescent emotion regulation.

Although all adolescents in our sample reported comparable levels of spontaneous self-distancing, associated decreases in emotional reactivity began around age 11 and grew stronger across adolescence. These findings are consistent with experimental work showing that with age adolescents become more adept at regulating emotion by imagining physical distance from a disturbing image (Silvers et al., 2012). While the cross-sectional design of this study limits conclusions about developmental change, the current results are consistent with the possibility that older adolescents are better equipped to capitalize on self-distancing processes than younger adolescents. We can only speculate as to the mechanisms underlying these trends. One possibility is that with age comes experience. Older adolescents, who have encountered more stressful life events (Larson \& Ham, 1993), are likely to have had more opportunities to practice regulatory strategies (Riediger \& Klipker, 2014), including self-distancing. Another possibility is that older adolescents' efforts could be bolstered by maturation of late-developing brain regions such as the prefrontal cortex, which is implicated in numerous regulatory processes (e.g., Casey et al., 2010; Ochsner \& Gross, 2008; Spear, 2000). It is also possible that age-related differences in the efficacy of selfdistancing could be attributable to the increasing diversity, frequency, and intensity of emotional experiences across adolescence; the transition to adulthood brings about increasing potential for conflict as adolescents seek independence from parents, become more invested in peer relationships, and navigate romantic relationships (Riediger \& Klipker, 2014). Our hope is that longitudinal research will further elucidate the role that development plays in this process. 


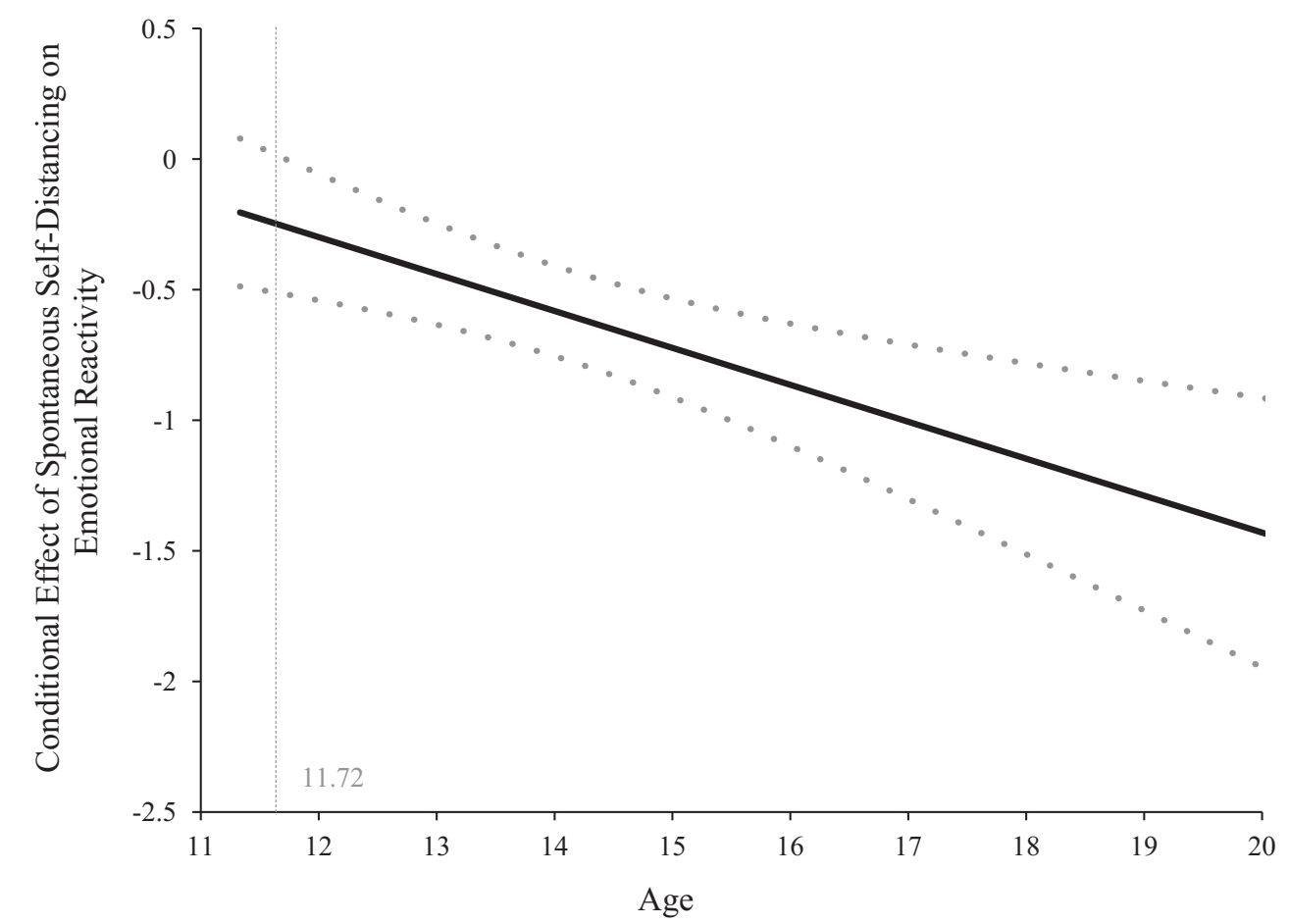

Figure 2. Conditional effect of spontaneous self-distancing on emotional reactivity as a function of age $(n=221)$. Dotted lines depict $95 \%$ confidence intervals. Dashed line marks the age at which the conditional effect reaches significance $(\alpha=.05)$.

Adolescents who spontaneously self-distanced tried to understand their problems, not avoid them (Ayduk \& Kross, 2010; Kross \& Ayduk, 2008, 2009; Kross et al., 2011; Kross, Gard, Deldin, Clifton, \& Ayduk, 2012). In this vein, it is important to highlight that we studied spontaneous self-distancing in the context of meaning-making in the current work - that is, as adolescents were trying to make sense of their negative past experience. Numerous studies (e.g., Kross \& Ayduk, 2011; Kross et al., 2005) have underscored the importance of this combination-self-distancing and "asking why"for achieving adaptive outcomes. Contrariwise, self-distancing without attempts to make meaning can induce further rumination (Kross et al., 2005) and negative emotion (Rood, Roelofs, Bogels, \& Arntz, 2012), and lead to avoidance (e.g., Kenny \& Bryant, 2007). Thus, the success of self-distancing might hinge on how adolescents approach their emotional challenges when spontaneously self-distancing.

Notably, self-distancing was associated with decreased blame, but not increased forgiveness. Although this may seem counterintuitive, reductions in blame need not lead to forgiveness. On average, even spontaneous self-distancers in our study indicated that they still placed some blame on others. Thus, it is possible that they were not yet ready to forgive or that their transgressors did not deserve forgiveness. Importantly, our data suggest that even without forgiveness, placing less blame on others can be adaptive.

\section{Limitations and Future Directions}

Future research is needed to explore the association between self-distancing and other negative emotions in adolescence. Self-distancing can have positive effects on anxiety (Kross et al., 2014) and depression (Kross \& Ayduk, 2009) in adults, but whether adolescents could benefit in the same way is unknown. Given the increasing prevalence of psychopathology across adolescence (e.g., Hankin et al., 1998; Kessler et al., 2005), it will be important to evaluate the role of psychological distancing on emotion regulation in clinical populations. In fact, the benefits of self-distancing have been shown to increase with greater emotional severity (Kross \& Ayduk, 2009; Kross et al., 2012), suggesting that adolescents who suffer from emotional psychopathologies might have the most to gain by using this strategy.

Due to the correlational design of this study, we cannot make causal claims on the effect of spontaneous self-distancing on emotional reactivity or the mediation model. However, it is important to note 
that the present analyses were based on previous experiments (Kross \& Ayduk, 2008; Kross et al., 2008; Kross et al., 2005; Kross et al., 2011; Kross et al., 2012), which have demonstrated causality by manipulating self-distancing. The current results bear a remarkable resemblance to those findings.

Finally, there appear to have been systematic errors in the interpretation of one item meant to assess reconstrual. The positive relation between adolescents' reported understanding of the event and emotional reactivity stands in contrast to the negative relation found between emotional reactivity and other reconstrual items in this and previous studies (e.g., Ayduk \& Kross, 2010). Given the current data, we cannot be sure what, if anything, might have been amiss with this item (e.g., comprehension, order effects), and this result should be interpreted with caution pending replication. Future research should include a more comprehensive measurement of the constructs studied here in order to establish more reliable composites.

\section{Conclusion}

Spontaneous self-distancing appears to be a natural response to negative emotion in adolescence, which with age is increasingly related to adaptive self-regulation of emotion. The present study provides a valuable glimpse into the inner workings of emotion regulation during a crucial period of social and emotional development and suggests that selfdistancing could be an important component of adaptive self-reflection in adolescence.

\section{References}

Ayduk, O., \& Kross, E. (2010). From a distance: Implications of spontaneous self-distancing for adaptive selfreflection. Journal of Personality and Social Psychology, 98, 809-829. doi:10.1037/a0019205

Campos, J. J., Frankel, C. B., \& Camras, L. (2004). On the nature of emotion regulation. Child Development, 75, 377-394. doi:10.1111/j.1467-8624.2004.00681.x

Carlson, S. M., \& Zelazo, P. D. (2008). Symbolic thought. In M. M. Haith \& J. B. Benson (Eds.), Encyclopedia of infant and early childhood development (pp. 288-297). Boston, MA: Elsevier/Academic Press.

Casey, B. J., Jones, R. M., Levita, L., Libby, V., Pattwell, S. S., Ruberry, E. J., . . Somerville, L. H. (2010). The storm and stress of adolescence: Insights from human imaging and mouse genetics. Developmental Psychobiology, 52, 225-235. doi:10.1002/dev.20447

Cocking, R. R., \& Renninger, K. A. (1993). The development and meaning of psychological distance. Hillsdale, NJ: Erlbaum.
Davis, J. I., Gross, J. J., \& Ochsner, K. N. (2011). Psychological distance and emotional experience: What you see is what you get. Emotion, 11, 438-444. doi:10.1037/ a0021783

Foa, E. B., Huppert, J. D., \& Cahill, S. P. (2006). Emotional processing theory: An update. In B. O. Rothbaum (Ed.), Pathological anxiety: Emotional processing in etiology and treatment (pp. 3-24). New York, NY: Guilford.

Fujita, K., Trope, Y., Liberman, N., \& Levin-Sagi, M. (2006). Construal levels and self-control. Journal of Personality and Social Psychology, 90, 351-367. doi:10.1037/ 0022-3514.90.3.351

Garnefski, N., \& Kraaij, V. (2006). Relationships between cognitive emotion regulation strategies and depressive symptoms: A comparative study of five specific samples. Personality and Individual Differences, 40, 1659-1669. doi:10.1016/j.paid.2005.12.009

Grossmann, I., \& Kross, E. (2010). The impact of culture on adaptive versus maladaptive self-reflection. Psychological Science, 21, 1150-1157. doi:10.1177/0956797610376655

Gruber, A., Harvey, J., \& Johnson, S. (2009). Reflective and ruminative processing of positive emotional memories in bipolar disorder and healthy controls. Behaviour Research and Therapy, 47, 697-704. doi:10.1016/ j.brat.2009.05.005

Hankin, B., Abramson, L., Moffitt, T., Silva, P., McGee, R., \& Angell, K. (1998). Development of depression from preadolescence to young adulthood: Emerging gender differences in a 10-year longitudinal study. Journal of Abnormal Psychology, 37, 128-140. doi:10.1037/ 0021-843X.107.1.128

Hayes, A. F. (2013). Introduction to mediation, moderation, and conditional process analysis: A regression-based approach. New York, NY: Guilford.

Heider, F. (1958). The psychology of interpersonal relations. Newark, NJ: Wiley.

Hodgins, M. J., \& Lander, J. (1997). Children's coping with venipuncture. Journal of Pain and Symptom Management, 13, 274-285. doi:10.1016/S0885-3924(96)00328-4

Johnson, P. O., \& Neyman, J. (1936). Tests of certain linear hypotheses and their application to some educational problems. Statistical Research Memoirs, 1, 57-93.

Katzir, M., \& Eyal, T. (2013). When stepping outside the self is not enough: A self-distanced perspective reduces the experience of basic but not of self-conscious emotions. Journal of Experimental Social Psychology, 49, 10891092. doi:10.1016/j.jesp.2013.07.006

Kelly, G. A. (1955). The psychology of personal constructs: I. A theory of personality. II. Clinical diagnosis and psychotherapy. Oxford, UK: Norton.

Kenny, L. M., \& Bryant, R. A. (2007). Keeping memories at an arm's length: Vantage point of trauma memories. Behaviour Research and Therapy, 45, 1915-1920. doi:10.1016/j.brat.2006.09.004

Kessler, R. C., Berglund, P., Demler, O., Jin, R., Merikangas, K. R., \& Walters, E. E. (2005). Lifetime prevalence and age-of-onset distributions of DSM-IV disorders in the National Comorbidity Survey Replication. Archives 
of General Psychiatry, 62, 593-602. doi:10.1001/archpsyc.62.6.593

Kross, E., \& Ayduk, O. (2008). Facilitating adaptive emotional analysis: Distinguishing distanced-analysis of depressive experiences from immersed-analysis and distraction. Personality and Social Psychology Bulletin, 34, 924-938. doi:10.1177/0146167208315938

Kross, E., \& Ayduk, O. (2009). Boundary conditions and buffering effects: Does depressive symptomology moderate the effectiveness of self-distancing for facilitating adaptive emotional analysis? Journal of Research in Personality, 43, 923-927. doi:10.1016/j.jrp.2009.04.004

Kross, E., \& Ayduk, O. (2011). Making meaning out of negative experiences by self-distancing. Current Directions in Psychological Science, 20, 187-191. doi:10.1177/ 0963721411408883

Kross, E., Ayduk, O., \& Mischel, W. (2005). When asking "why" does not hurt: Distinguishing rumination from reflective processing of negative emotions. Psychological Science, 16, 709-715. doi:10.1111/j.1467-9280.2005.01600.x

Kross, E., Bruehlman-Senecal, E., Park, J., Burson, A., Dougherty, A., Shablack, H., ... Ayduk, O. (2014). Self-talk as a regulatory mechanism: How you do it matters. Journal of Personality and Social Psychology, 106, 304-324. doi:10.1037/a0035173

Kross, E., Duckworth, A., Ayduk, O., Tsukayama, E., \& Mischel, W. (2011). The effect of self-distancing on adaptive vs. maladaptive self-reflection in children. Emotion, 11, 1032-1039. doi:10.1037/a0021787

Kross, E., Gard, D., Deldin, P., Clifton, J., \& Ayduk, O. (2012). Asking why from a distance: Its cognitive and emotional consequences for people with major depressive disorder. Journal of Abnormal Psychology, 121, 559569. doi: $10.1037 / \mathrm{a} 0028808$

Larson, R., Csikszentmihalyi, M., \& Graef, R. (1980). Mood variability and the psychosocial adjustment of adolescents. Journal of Youth and Adolescence, 9, 469-490. doi:10.1007/BF02089885

Larson, R., \& Ham, M. (1993). Stress and "storm and stress" in early adolescence: The relationship of negative events with dysphoric affect. Developmental Psychology, 29, 130-140. doi:10.1037/0012-1649.29.1.130

Larson, R., \& Lampman-Petraitis, C. (1989). Daily emotional states as reported by children and adolescents. Child Development, 60, 1250-1260. doi:10.2307/ 1130798

Larson, R. W., Moneta, G., Richards, M. H., \& Wilson, S. (2002). Continuity, stability, and change in daily emotional experience across adolescence. Child Development, 73, 1151-1165. doi:10.1111/1467- 8624.00464

Liberman, N., \& Trope, Y. (2008). The psychology of transcending the here and now. Science, 322, 1201-1205. doi:10.1126/science. 1161958

Maglio, S. J., Trope, Y., \& Liberman, N. (2013). Distance from a distance: Psychological distance reduces sensitivity to any further psychological distance. Journal of Experimental Psychology: General, 142, 644-657. doi: $10.1037 / a 0030258$
McRae, K., Gross, J. J., Weber, J., Robertson, E. R., SokolHessner, P., Ray, R. D., . . Ochsner, K. N. (2012). The development of emotion regulation: An fMRI study of cognitive reappraisal in children, adolescents and young adults. Social Cognitive and Affective Neuroscience, 7, 11-22. doi:10.1093/scan/nsr093

Mischel, W., \& Baker, N. (1975). Cognitive appraisals and transformations in delay behavior. Journal of Personality and Social Psychology, 31, 254-261. doi:10.1037/h0076272

Mischel, H. N., \& Mischel, W. (1983). The development of children's knowledge of self-control strategies. Child Development, 54, 603-619. doi:10.2307/1130047

Mischel, W., \& Rodriguez, M. L. (1993). Psychological distance in self-imposed delay of gratification. In R. R. Cocking \& K. A. Renninger (Eds.), The development and meaning of psychological distance (pp. 109-121). Hillsdale, NJ: Erlbaum.

Nolen-Hoeksema, S., Wisco, B., \& Lyubomirsky, S. (2008). Rethinking rumination. Perspectives on Psychological Science, 3, 400-424. doi:10.1111/j.1745-6924.2008.00088.x

Ochsner, K. N., \& Gross, J. J. (2008). Cognitive emotion regulation: Insights from social cognitive and affective neuroscience. Current Directions in Psychological Science, 17, 153-158. doi:10.1111/j.1467-8721.2008.00566.x

Park, C. L. (2010). Making sense of the meaning literature: An integrative review of making meaning and its effects on adjustment to stressful life events. Psychological Bulletin, 136, 257-301. doi:10.1037/a0018301

Pennebaker, J. W., \& Chung, C. K. (2007). Expressive writing, emotional upheavals, and health. In H. S. Friedman \& R. C. Silver (Eds.), Foundations of health psychology (pp. 263-284). New York, NY: Oxford University Press.

Prencipe, A., \& Zelazo, P. D. (2005). Development of affective decision making for self and other: Evidence for the integration of first- and third-person perspectives. Psychological Science, 16, 501-505. doi:10.1111/ j.0956-7976.2005.01564.x

Riediger, M., \& Klipker, K. (2014). Emotion regulation in adolescence. In J. J. Gross (Ed.), Handbook of emotion regulation (2nd ed., pp. 187-202). New York, NY: Guilford.

Roecker, C. E., Dubow, E. F., \& Donaldson, D. (1996). Cross-situational patterns in children's coping with observed interpersonal conflict. Journal of Clinical Child Psychology, 25, 288-299. doi:10.1207/s15374424jccp 2503_5

Rood, L., Roelofs, J., Bogels, S. M., \& Arntz, A. (2012). The effects of experimentally induced rumination, positive reappraisal, acceptance, and distancing when thinking about a stressful event on affect states in adolescents. Journal of Abnormal Child Psychology, 40, 73-84. doi:10.1007/s10802-011-9544-0

Sigel, I. E. (1970). The distancing hypothesis: A causal hypothesis for the acquisition of representational thought. In M. R. Jones (Ed.), Miami Symposium on the Prediction of Behavior, 1968 (pp. 99-118). Coral Gables, FL: University of Miami Press. 
Silvers, J. A., McRae, K., Gabrieli, J. D., Gross, J. J., Remy, K. A., \& Ochsner, K. N. (2012). Age-related differences in emotional reactivity, regulation, and rejection sensitivity in adolescence. Emotion, 12, 1235-1247. doi:10.1037/a0028297

Spear, L. P. (2000). The adolescent brain and age-related behavioral manifestations. Neuroscience and Biobehavioral Reviews, 24, 417-463. doi:10.1016/S0149-7634(00)00014-2

Trope, Y., \& Liberman, N. (2010). Construal-level theory of psychological distance. Psychological Review, 117, 440-463. doi:10.1037/a0018963

Verduyn, P., Van Mechelen, I., Kross, E., Chezzi, C., \& Van Bever, F. (2012). The relationship between self-distancing and the duration of negative and positive emotional experiences in daily life. Emotion, 12, 1248-1263. doi:10.1037/a0028289

White, R. E., \& Carlson, S. M. (in press). What would Batman do? Self-distancing improves executive function in young children. Developmental Science.

Williams, K., \& McGillicuddy-De Lisi, A. (1999). Coping strategies in adolescents. Journal of Applied Developmental Psychology, 20, 537-549. doi:10.1016/S0193-3973(99) 00
Wilson, T. D., \& Gilbert, D. T. (2008). Explaining away: A model of affective adaptation. Perspectives on Psychological Science, 3, 370-386. doi:10.1111/j.1745-6924.2008. 00085.x

Wisco, B. E., \& Nolen-Hoeksema, S. (2011). Effect of visual perspective on memory and interpretation in dysphoria. Behaviour Research and Therapy, 49, 406-412. doi:10.1016/j.brat.2011.03.012

Zelazo, P. D. (2004). The development of conscious control in childhood. Trends in Cognitive Sciences, 8, 12-17. doi:10.1016/j.tics.2003.11.001

\section{Supporting Information}

Additional supporting information may be found in the online version of this article at the publisher's website:

Appendix S1. Analyses Using a Two-Item Spontaneous Self-Distancing Composite Score

Appendix S2. Analyses Using a Three-Item Reconstrual Composite 